\title{
Masonry Walls Retrofitted with Vertical FRP Rebars
}

\author{
Simona Coccia ${ }^{1}$, Fabio Di Carlo ${ }^{1}$ and Stefania Imperatore ${ }^{2, *}$ (i) \\ 1 Department of Civil Engineering and Computer Science Engineering (DICII), \\ University of Rome “Tor Vergata”, Via del Politecnico 1, 00133 Rome, Italy; coccia@ing.uniroma2.it (S.C.); \\ di.carlo@ing.uniroma2.it (F.D.C.) \\ 2 Department of Engineering, Niccolò Cusano University, Via Don Carlo Gnocchi 3, 00166 Rome, Italy \\ * Correspondence: stefania.imperatore@unicusano.it
}

Received: 6 March 2020; Accepted: 30 March 2020; Published: 3 April 2020

\begin{abstract}
The out-of-plane behaviour of the walls as a consequence of an earthquake is the main vulnerability of existing masonry structures. In the case of rigid in compression not tensile resistant material, incremental dynamic analyses may be employed to evaluate the effective strength of a rocking element. When the seismic capacity of the wall is inadequate, retrofit interventions are required to assure an acceptable safety level. Conventional seismic retrofitting techniques on masonry walls influence the seismic performance of the element, which typically is modified in an out-of-plane bending behaviour. In this paper, analytical investigations are presented to investigate the possibility of a seismic retrofitting intervention able to increase the seismic strength of the wall without modifying its seismic behaviour. The analysed retrofitting technique consists in the application of composite vertical bars either in the middle section of the wall or at its external surfaces. The seismic behaviour of the retrofitted masonry wall is analytically evaluated by means of a parametric incremental dynamic analysis, carried out with an ad hoc in-house software. The effectiveness of the intervention is analysed in terms of level of seismic improvement, defined as the ratio between the seismic capacity of the reinforced and unreinforced walls.
\end{abstract}

Keywords: masonry wall; rocking behaviour; seismic retrofitting; FRP composite rebar

\section{Introduction}

Every seismic sequence involving an old town, from the Friuli Earthquake in 1976 up to the Central Italy Earthquake in 2016, highlights the high vulnerability of ancient unreinforced masonry buildings [1-6]. This vulnerability depends either on the structural arrangement—strictly related to the resistance against dynamic horizontal actions-or on the masonry quality. Specifically, structures characterized by random and rubble/irregular stone experience complete collapses or serious damages, while perfectly squared or roughly-cut stone masonry enable a marked increase in the seismic resistance. The damage pattern strictly depends on the capacity of the structure to develop a box behaviour [7,8], typically lacking in old masonry buildings. Redistribution of horizontal loads between different elements significantly affects the seismic behaviour of the building, in which flexibility of horizontal diaphragms [9] and existing connections between orthogonal walls or between horizontal diaphragms and walls play a central role. Actually, out-of-plane collapses represent the most serious life-safety hazard for old masonry building [10].

For a proper seismic assessment of masonry elements, both material mechanical properties and masonry morphology are worth of interest. At the aim, it is important to underline that poor mechanical properties and insufficient masonry detailing ease the development of crumbling phenomena, such as the splitting of the wall into separate leaves. In this case, mechanical models have to take into account local masonry collapses [11]. Vice versa, in case of good mechanical properties and compliance 
with the current state of the art, the masonry element, when subjected to out-of-plane actions, assumes a monolithic behaviour and cracks subdividing into distinct macro-elements. A model of rigid body excited into a rocking motion can be adopted to simulate the behaviour of the masonry element [12-14], whose effectiveness has been recently proved through dynamic tests performed on real walls [15] and by the subsequent comparison with analytical and numerical models [16].

Depending on the typology of restraints and on the location of the masonry element within the structure, different mechanisms may take place [17]. It is nowadays well assessed that, in presence of poor connections with external or internal perpendicular walls, out-of-plane behaviour of masonry piers and spandrels represents the greater structural vulnerability of existing masonry building [18-22]. Advanced analysis techniques, involving both theoretical approaches $[15,23-31]$ and numerical models [11,16,32-34], allow to accurately evaluate the seismic capacity of the masonry element and to direct engineers to the definition of proper retrofitting interventions, required to ensure an adequate safety level in case of low structural capacity. Well-designed classical retrofitting interventions can improve the seismic strength of the masonry macro-element but, on the other hand, they can change the collapse mode, inhibiting the simple overturning mechanism and then modifying the structural behaviour of the entire structure. As an example [35-38]: the steel chains and belting, increasing the out-of-plane wall strength, can inhibit the overturning kinematism transforming it into vertical bending; external steel reinforcement technique, due to their large stiffness, tends to localize seismic stresses; the mesh reinforcement, as well as the FRP rehabilitation systems, significantly improve both ductility and in-plane capacity of the element, but the out-of-plane capacity is guaranteed only if adequate connections are introduced and in this case the seismic behaviour turns into a bending out of plane.

In the present paper, a novel retrofitting technique, taking the cue from a typology of intervention frequently used in the past and nowadays recovered, is analysed: the vertical FRP rebars. The adoption of this retrofitting methodology in several case studies seems to confirm its effectiveness. As an example, in 1999 the Bell-Tower of the S. Giorgio Church (Trignano, San Martino in Rio, Reggio Emilia, Italy) was retrofitted with vertical unbonded post-tensioned steel tie bars coupled to shape memory alloy devices, located at the internal corner of the structure [39]. As a proof of the effectiveness of the intervention, no relevant damages were detected after the earthquakes occurred on June 18th 2000 (4.5 on the Richter Scale) and on May 20th and 29th 2012 (5.9 and 5.8 on the Richter Scale, respectively). Similar retrofitting intervention, based on the application of prestressing vertical rebars inside the existing masonry, can be found in other bell-towers situated in the region of Reggio-Emilia [40,41].

In [42], the results of shaking table tests performed on 1:4 scaled masonry buildings retrofitted with post-tensioned external vertical tendons are shown. Due to an increase in structural stiffness and damping, the retrofitted specimen was characterized by smaller storey displacements. Furthermore, the failure mode, initially governed by the out-of-plane flexural strength moved to a collapse one due to the in-plane shear strength. The behaviour of the Chemistry and College Hall buildings in the Arts Centre of Christchurch, observed during the 2010 Canterbury earthquake sequence, confirmed the experimental results [43]. The structures, retrofitted in 1984 by introducing external vertical post-tensioned strands, were affected by a low post earthquake mean damage level, despite of a significant decrease in the prestressing level and of a corrosion induced deterioration involving several tendons.

It is worth to highlight that retrofitting systems composed by vertical tendons improve both out-of-plane and in-plane strengths of the masonry wall and that the seismic improvement strongly depends on the applied pre-stressing force. This latter should be evaluated in function of both possible pre-stressing losses (due to masonry long-term creep, relaxation of prestressing tendons, anchorage damages and prestressing losses due to the environmental condition) and strength of the existing masonry. Numerical studies $[44,45]$ proved that the displacement capacity of retrofitted structures reduces with increasing pre-stressing level. For an optimal energy dissipation, a prestressing level lower than $15 \%$ of the vertical load should be applied. Unfortunately, in order to avoid any prestressing losses, such a level should be increased up to values for which the retrofitting intervention 
becomes quite ineffective in terms of displacement capacity. Moreover, it is worth to remark the possibility of a variation of the failure mode of the retrofitted masonry structures induced by the retrofitting system.

This paper deals with the seismic behaviour of masonry walls reinforced with external or internal vertical unbonded tendons, without any pre-stressing action, in order to avoid any change in the failure mechanism. A theoretical study is carried out moving from previous researches carried out by the same authors $[46,47]$. The intervention technique, regarded as an application of vertical restrains connected to a rocking element, can consequently be studied by following the analytical model firstly proposed in [48-50], in the framework of the dynamics of a rigid rocking element.

Since durability of metallic rebars represents also a weak-point of the retrofitting technique, the use of composite materials is accounted for. The vertical reinforcement may take the form of strips or bars, applied in the middle section of the wall or at its external surfaces (Figure 1). In both cases, the restrainers should be not adherent to the nearby masonry. According to the retrofitting intervention depicted in [43], a proper anchorage can be ensured, for both inside and outside arrangement, by means of composite or steel end plates or concrete pockets (Figure 2).

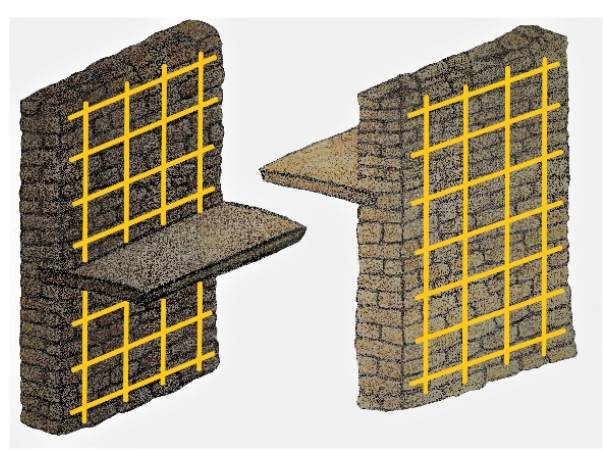

(a)

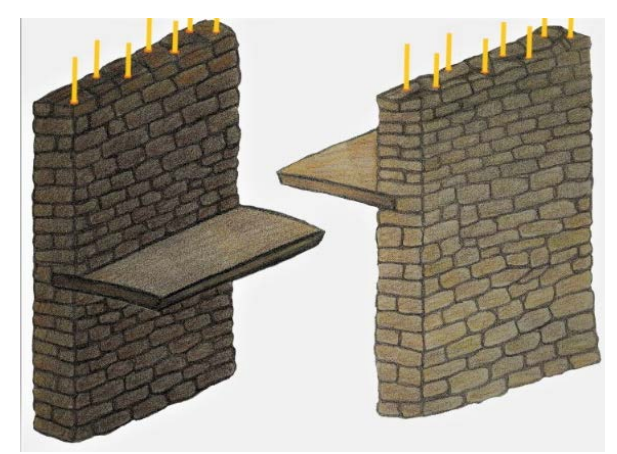

(b)

Figure 1. Schemes of the investigated retrofitting techniques: (a) external, (b) centred vertical rebars.

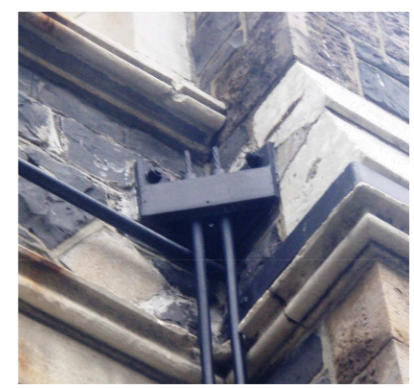

(a)

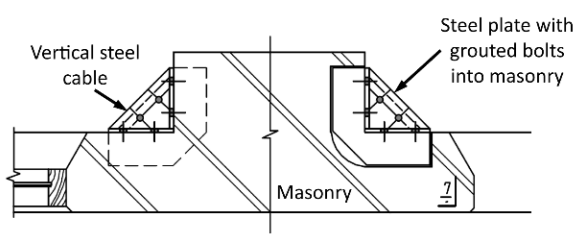

(b)

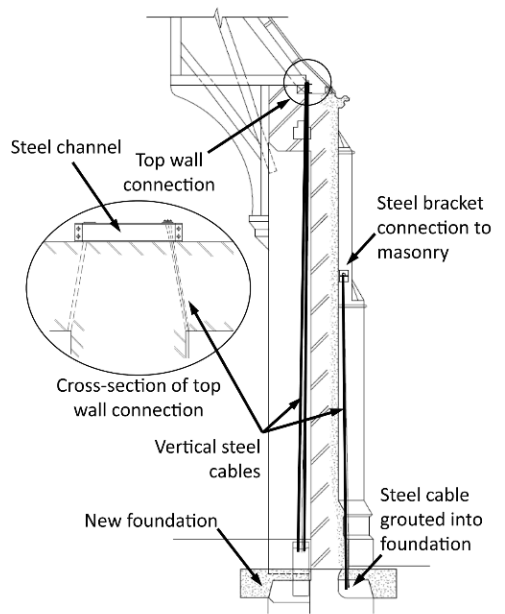

(c)

Figure 2. Detail of the anchorages for the external retrofitting intervention (from [43]): (a) real image of the external connection on the Chemistry building in Christchurch; (b) schematic representation of the detail in (a); (c) retrofit cross-section in the Great Hall of the Canterbury College with a detail of the bottom anchorage. 
Construction needs, admitted invasiveness of the intervention and requested efficiency are all parameters influencing the choice of the position of the composite restraints. External vertical anchors (Figure 1a) are characterized by a greater efficiency, represent a reversible intervention and may be speedily applied on the wall. This last property can represent a strong point in case of post-earthquake priority intervention. In addition, there are aspects of controllability, post-tensioning and substitutability. On the other side, if the masonry element undergoes to movement along only the outward direction (i.e., one-sided motion), the internal grid counteracts the seismic action and the external grid has the function of "packaging" for the masonry wall. The external vertical anchors are characterized by a higher aesthetic invasiveness. Vice versa, internal centred anchors (Figure 1b), are not visible but at the same time characterized by a greater invasiveness and realization industriousness, as so as by a lower structural efficiency. Obviously, the intervention typology to be adopted should be accurately chosen also according to a cost-benefit analysis.

In the present paper, the effectiveness of the retrofitting technique previously described is analytically investigated by means of a parametric analysis, carried out by varying geometry of the masonry blocks, characteristics of the seismic input and material of the anchoring system. Furthermore, two different methodologies of intervention, involving centred or external elastic-brittle vertical anchors, and two different collapse mechanisms, bilateral and unilateral (i.e., two-sided and one-sided rocking) are considered. The seismic capacity of the reinforced elements, compared to the dynamic collapse acceleration of the unreinforced masonry block, gives the level of seismic improvement reachable thanks to the retrofitting intervention.

\section{Dynamic Equation of Motion of the Retrofitted Masonry Wall}

The analytical model used to estimate the seismic improvement of rigid masonry blocks retrofitted with vertical composite rebars starts from the classical theory of the freestanding block involved in a rocking motion [51,52]. The masonry wall, characterized by width $B$, height $H$ and length $L$ (Figure 3a), when excited along the out-of-plane direction, can be modelled considering a unitary length. According to the classical approach, the dynamic response of the wall is modelled considering a negligible body deformability and a friction coefficient sufficiently large to prevent horizontal sliding, therefore, during the motion, only rigid rotations about the two edges of the base section of the block, identified by points $O$ and $O^{\prime}$ in Figure 3b, are admitted. In the following, the geometry of the reference element is defined by the radial distance $R$, measured from the centre of gravity $G$ to each one of the two centres of rotation $O$ and $O^{\prime}$ and the angle of slenderness $\alpha$, included between the diagonal $R$ and the vertical side of the block (Figure $3 b$ ).

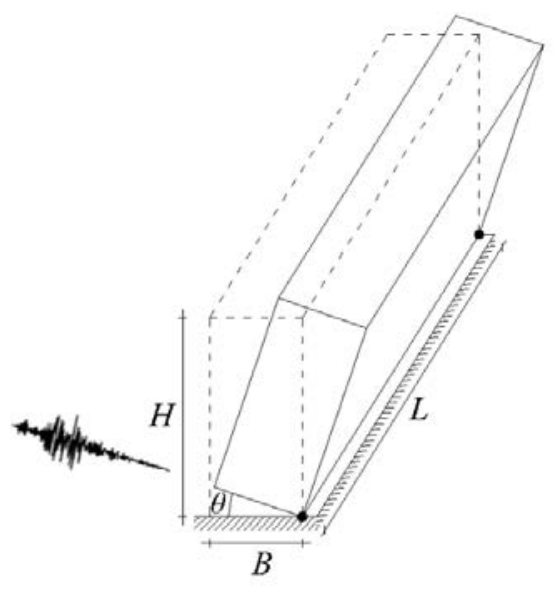

(a)

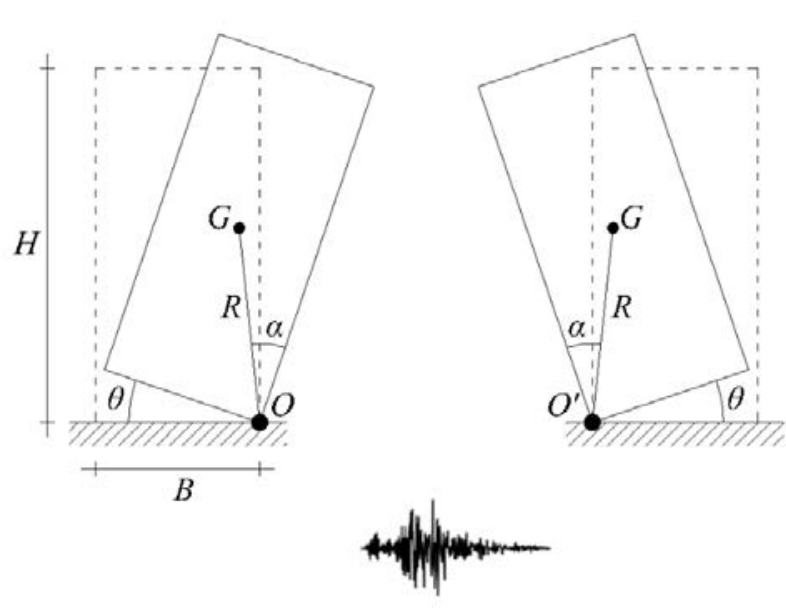

(b)

Figure 3. Model of the wall: (a) three-dimensional view; (b) model geometry. 
The dynamic equation of the motion of the block is found by applying the Lagrange equation:

$$
\frac{d}{d t} \frac{\partial T}{\partial \dot{q}_{k}}-\frac{\partial T}{\partial q_{k}}+\frac{\partial U}{\partial q_{k}}=Q_{e s t}
$$

where $(\cdot)$ means differentiation with respect to time $t, T$ and $U$ are the kinetic and potential energy respectively, $Q_{e s t}$ is the work of non-conservative forces and the Lagrangian parameter $q_{k}$ is taken to be equal to the rotation $\theta$ of the block.

Simple architectural elements, such as boundary or parapet walls, can be modelled as a freestanding rocking block [26], while in presence of transverse walls and horizontal structural elements, the monolithic masonry wall can be studied as a rigid block undergoing to a unilateral motion [23]. This last hypothesis is clearly valid in case of missing connections between the rocking element and the transverse walls or horizontal structures. In the following, both cases of bilateral and unilateral motions are addressed, namely two-sided and one-sided rocking motion (Figure 4).

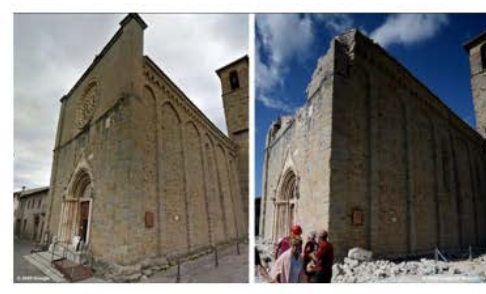

(a)

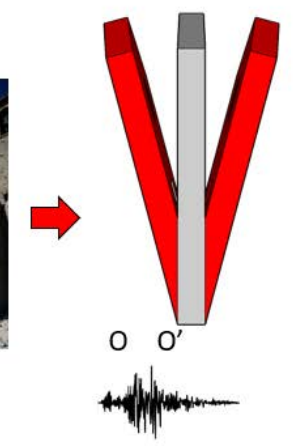

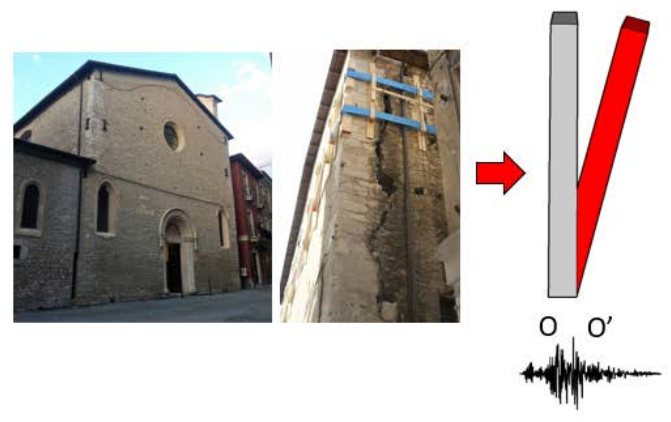

(b)

Figure 4. Collapse mechanisms occurring in the out-of-plane behaviour: (a) two-side rocking motion (images from https://www.dw.com/de/ein-beben-ersch\%C3\%BCttert-italiens-kultur/a-19515621-0); (b) one-side rocking motion (images from http://www.lct-architettura.it/Restauri/\&id=91).

In order to solve Equation (1), the kinetic energy $T$ and the work of the un-conservatives forces $Q_{\text {est }}$ have to be defined. Being not influenced by the presence of the vertical rebars, they can be expressed as:

$$
\begin{gathered}
T=\frac{1}{2} I_{o} \dot{\theta}^{2}, \\
Q_{\text {est }}=-m R \ddot{u}(t) \cos [\alpha \cdot \operatorname{sgn}(\theta)-\theta],
\end{gathered}
$$

where $I_{0}$ the moment of inertia about the two centres of rotation $O$ and $O^{\prime}, \dot{\theta}$ is the angular velocity of the centre of mass, $m$ is the mass of the element, $\ddot{u}(t)$ the time-dependent ground motion acceleration and $\theta$ is the rotation of the block, which is characterized by a slenderness $\alpha$.

In case of retrofitted block (Figure 5), the potential energy $U$ accounts for both contributions of block and elastic restraint:

$$
U=U_{m}+U_{r}
$$

Where the term $U_{m}$ referring to the masonry block is:

$$
U_{m}=m g R \cos [\alpha \cdot \operatorname{sgn}(\theta)-\theta],
$$

And the term $U_{r}$ regarding the vertical rebar is:

$$
U_{r}=\frac{1}{4} e^{2} \frac{E A}{R \cos (\alpha)},
$$


where $E$ and $A$ are the elastic modulus and the total area of the rebar, respectively. The parameter $e$, included in Equation (6) and representing the elongation of the restraint due to the rocking motion, can be expressed in function of the rotation $\theta$ as:

$$
e=2 b_{r} \sin \left(\frac{\theta}{2}\right)
$$

where the distance $b_{r}$ of the restraint from the centre of rotation $O$ is equal to:

$$
b_{r}=R \sin (\alpha),
$$

in case of centred retrofitting system (Figure 5a) or:

$$
b_{r}=2 R \sin (\alpha),
$$

in case of external restraints (Figure 5b).

Substituting the previous quantities in Equation (1) and solving the various derivatives, the equation of motion of the vertically restrained rocking element can be finally obtained:

$$
\ddot{\theta}=-p^{2}\left\{\sin (\alpha \operatorname{sgn} \theta-\theta)+\frac{\ddot{u}(t)}{g} \cos (\alpha \operatorname{sgn} \theta-\theta)+\sin \alpha \sin \theta \tan \alpha \frac{r p}{2} \frac{E A}{m g}\right\},
$$

where $p^{2}=m g R / I_{0}$ is the frequency parameter of the block and $r_{p}$ is a parameter equal to 1 or 4 in case of centred or external rebars, respectively.

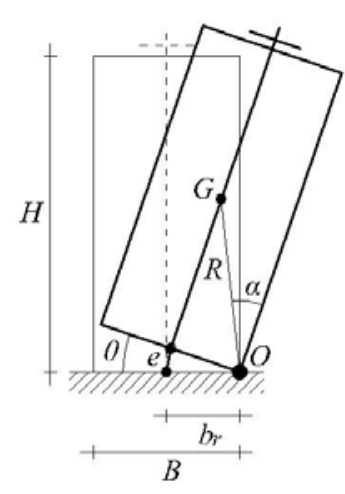

(a)

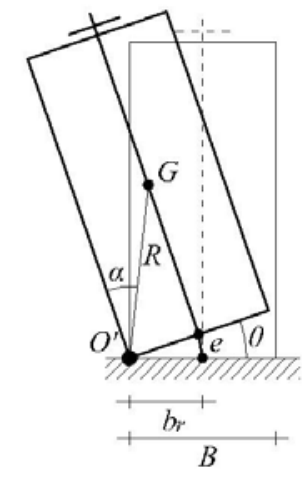

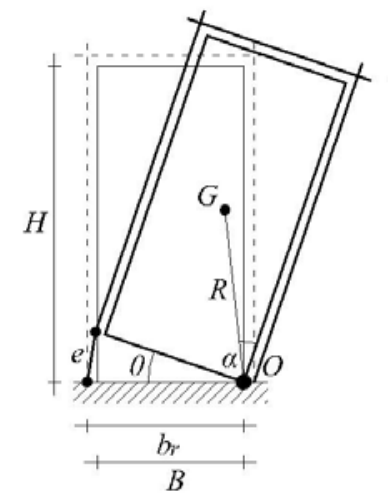

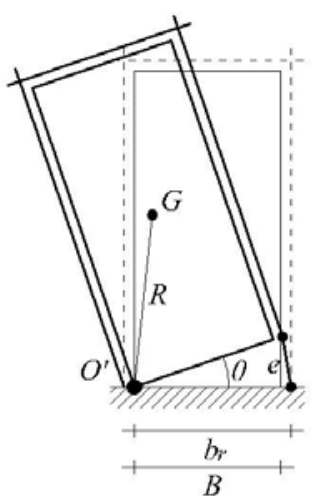

(b)

Figure 5. Model geometry of the block retrofitted with centred (a) or external (b) vertical rebars.

It is worth to highlight the existence of an ultimate condition of the vertical rebars. In case of centred rebars, for both bilateral and unilateral mechanisms, the elastic restraint influences the dynamic response of the rocking block up to the achievement of an ultimate condition analytically described by a maximum value of rotation $\theta_{\max }$ defined as:

$$
\theta_{\max }=2 \sin ^{-1}\left(\frac{\varepsilon_{\max } H}{2 b_{r}}\right),
$$

where $\varepsilon_{\max }$ represents the collapse strain of the composite material of which the rebars are made. According to [53], a reduction of the strength of the vertical restraints due to cyclic loads can be properly accounted for through a strain multiplier equal to 0.5 valid for all chosen fibres. Vice versa, in case of external retrofitting system, the collapse state depends on the analysed mechanism. If the wall undergoes to a bilateral motion, only one of the two systems of lateral rebars works for a clockwise or anticlockwise rotation of the block. Specifically, the rebars opposite to the centre of rotation elongate, 
contributing to the potential energy $U_{r}$ and influencing the dynamic motion of the rocking block. On the contrary, the reinforcement located near the centre of rotation exerts only a retaining action. Consequently, if one of the two systems of rebars breaks, the other one can continue to restrain the element. At the instant in which the reinforcement breaks, an instantaneous variation of the block velocity occurs. According to the Principle of Conservation of Energy, if in a system only conservative forces act, the sum of kinetic energy, gravitational potential energy and elastic potential energy remains constant, in the two time instants immediately before (-) and after $(+)$ the failure of the rebar:

$$
\frac{1}{2} I_{0} \dot{\theta}_{-}^{2}+U_{r}=\frac{1}{2} I_{O} \dot{\theta}_{+}{ }^{2},
$$

Finally, once that the retrofitting system is broken, the wall can continue its rocking motion as an unreinforced element. This condition means that the term $U_{r}$ in Equation (10) becomes equal to zero and the motion of the block is governed by the classical equation of the rocking element.

Energy dissipation phenomena taking place when impacts occur at the base, in case of two-sided rocking, or at the base and at the top section, in case of one-sided rocking, are accounted for through a coefficient of restitution $r$, joining the post-impact and pre-impact velocities of the block. This coefficient is conventionally defined according to the Conservation of the Angular Momentum and to the classical hypotheses of infinitesimal duration of the impact, no sliding and instantaneous variation of velocity during impact [23-50]. Specifically, with reference to a rectangular block, the coefficient of restitution is:

$$
r=\left(1-\frac{3}{2} \sin ^{2} \alpha\right)^{2}
$$

in case of bilateral mechanism [51], or:

$$
r=\left[\left(1-\frac{3}{2} \sin ^{2} \alpha\right)^{2}\left(1-\frac{3}{2} \cos ^{2} \alpha\right)\right]^{2}
$$

for unilateral mechanism [24].

The Equation (10) is numerically solved considering a time-dependent ground motion acceleration increasing until the collapse of the wall that is conventionally represented by the attainment at the end of the seismic input of a value of rotation equal to the angle of slenderness $\alpha$ of the wall.

\section{Parametric Analyses}

In this section, a parametric analysis is performed in order to investigate the influence of the vertical composite restraints on the dynamic behaviour of the masonry wall. In order to consider an element having a seismic response reasonably comparable to a monolithic behaviour, a solid brick and lime mortar masonry has been adopted, characterized by a specific weight equal to $18 \mathrm{kN} / \mathrm{m}^{3}$.

The analyses are carried out by varying geometry of the masonry wall, features of the seismic input, typology of overturning mechanism (i.e., two-sided or one-sided rocking) and position, geometrical percentage and material properties of the composite rebars. In particular three different angles of slenderness $\left(\alpha=5^{\circ}, \alpha=7.5^{\circ}\right.$ or $\left.\alpha=10^{\circ}\right)$ are considered with a height $H$ ranging from $3 \mathrm{~m}$ to $8 \mathrm{~m}$.

Three different composite materials are considered in the analyses, glass-fibres or GFRP, basalt-fibres or BFRP and carbon-fibres or CFRP, whose constitutive relationships are shown in Figure 6. The area of the vertical rebars is set as a percentage $\rho$ of the cross-section of the masonry wall. Specifically, three percentages are considered in the analyses, equal to $1 \%$, $2 \%$ o and $3 \%$ o. In case of external rebars, the previous percentages refer only to the active restraints; this means that double the amount of reinforcement is needed. 


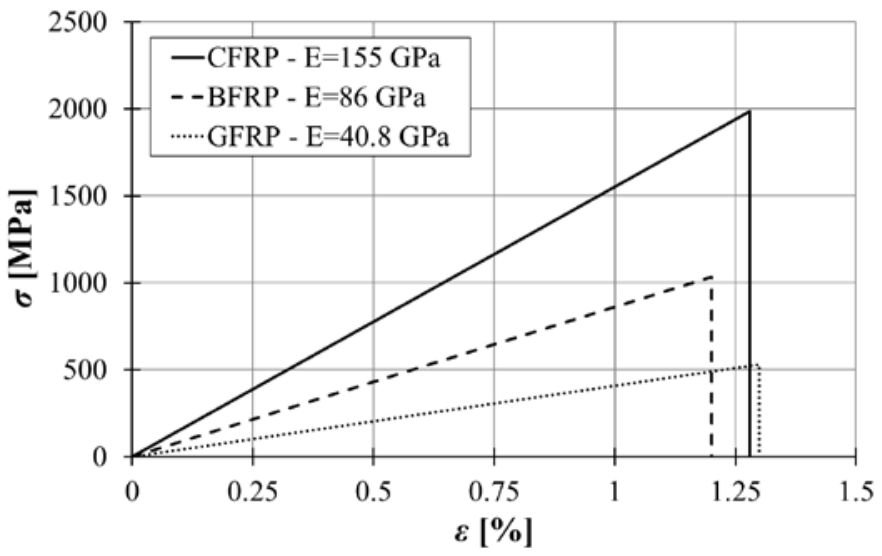

Figure 6. Constitutive relationships of the retrofitting composite materials.

The analyses are performed using artificial spectrum-compatible ground motions. In order to investigate the influence of the characteristics of the seismic input other than the peak ground acceleration (PGA) on the response of the masonry element, three elastic acceleration response spectra, called $A 1, A 2$ and $A 3$, shown in Figure 7, have been considered. In particular, these latter are characterized by the same PGA, equal to $0.106 \mathrm{~g}$, but different values of the lower and upper limits of the periods of the constant spectral acceleration branch $T_{B}$ and $T_{C}$. According to the Code provisions [54], seven artificial accelerograms are generated for each response spectrum, in order to match the elastic response spectra for $5 \%$ viscous damping, with a minimum duration of the stationary part of the accelerograms equal to $10 \mathrm{~s}$. In the maximum range of periods between $0.15 \mathrm{~s}-2.0 \mathrm{~s}$ and $0.15 \mathrm{~s}-2 T$, where $T$ is the fundamental elastic period of the structure in the direction along which the accelerogram is applied, no value of the mean $5 \%$ damping elastic spectrum of all the time histories, is less than $90 \%$ of the corresponding value of the $5 \%$ damping elastic response spectrum.

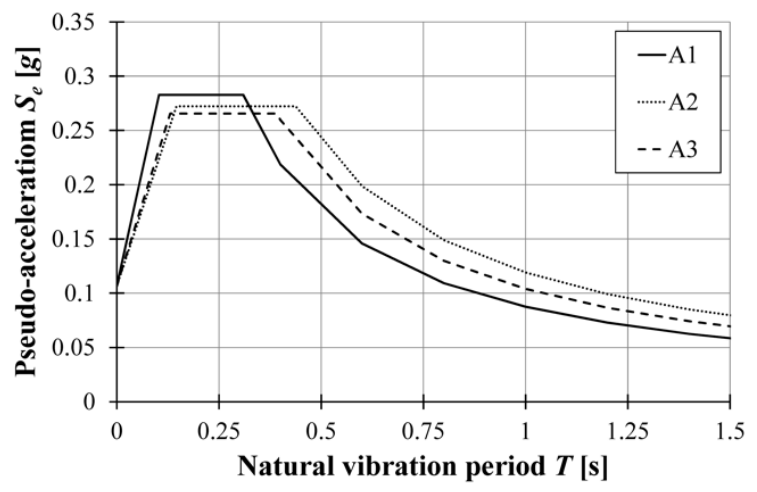

\begin{tabular}{|c|c|c|c|}
\hline Spectrum & PGA $[\mathrm{g}]$ & $\mathrm{T}_{\mathrm{B}}[\mathrm{s}]$ & $\mathrm{TC}[\mathrm{s}]$ \\
\hline \multirow{2nnn}{*}{$\mathrm{A} 1$} & \multirow{3}{*}{0.106} & 0.103 & 0.309 \\
\cline { 1 - 1 } \cline { 4 - 4 } $\mathrm{A} 2$ & 0.146 & 0.437 \\
\cline { 1 - 1 } $\mathrm{A} 3$ & & 0.13 & 0.391 \\
\hline
\end{tabular}

Figure 7. Elastic response spectra $S_{e}(T)$.

All parameters used in the numerical analyses are summarized in Table 1.

Table 1. Parameters considered in the parametric study.

\begin{tabular}{cc}
\hline $\boldsymbol{H}(\boldsymbol{m})$ & $3-4-5-6-7-8$ \\
\hline$\alpha$ & $5-7.5-10$ \\
\hline$\rho$ & $1 \%$ o- $2 \%$-3\%o \\
\hline Material & GFRP-BFRP-CFRP \\
\hline Spectrum & $A 1-A 2-A 3$ \\
\hline
\end{tabular}


A measure of the seismic behaviour of the element is given by the force reduction factor $q$, representing the ratio between the dynamic collapse acceleration $a_{d y n}$ causing the collapse of the masonry element and the acceleration of activation of the rocking motion $a_{R M}$ :

$$
q=a_{d y n} / a_{R M}
$$

With the aim to evaluate the dynamic collapse acceleration $a_{d y n}$, the equation of motion Equation (10) is numerically solved using a Newmark trapezoidal rule [55]. The seismic input $\ddot{\mathrm{u}}(\mathrm{t})$, represented by a ground motion with a defined peak ground acceleration PGA, is increased by means of a multiplier $C$, up to the attainment of the overturning condition. The effectiveness of the adopted method and of the integration procedure for modelling the rocking behaviour of the masonry element has been demonstrated in [28], through a comparison with the outcomes of an experimental campaign performed by [24] on a masonry wall made of tuff units. The adopted procedure allows evaluating the force reduction factor as:

$$
q=\frac{C \cdot P G A}{a_{R M}}
$$

\subsection{Unrestrained Rocking Block}

The force reduction factor of the unrestrained rocking block is thus evaluated as the average of the values obtained using the seven accelerograms in the numerical integration of the equation of motion. As an example, Figure 8 shows the trend of the force reduction factor with increasing height $H$, for an unreinforced block with a slenderness angle $\alpha$ equal to $7.5^{\circ}$, varying the seismic input and the type of mechanism. An increase of the $q$ factor with the height is found, since a scale effect exists, according to which the larger of two geometrically similar blocks is more stable than the smaller one [51]. The motivation consists in the fact that, for fixed values of the angle of slenderness, the acceleration of activation of the motion $a_{R M}$ is constant varying the height $H$ of the element, while the dynamic collapse acceleration $a_{d y n}$ increases with increasing $H$. With reference to masonry elements characterized by the same geometry, the values of the $q$ factor are higher in case of one-sided mechanism than in case of bilateral one.
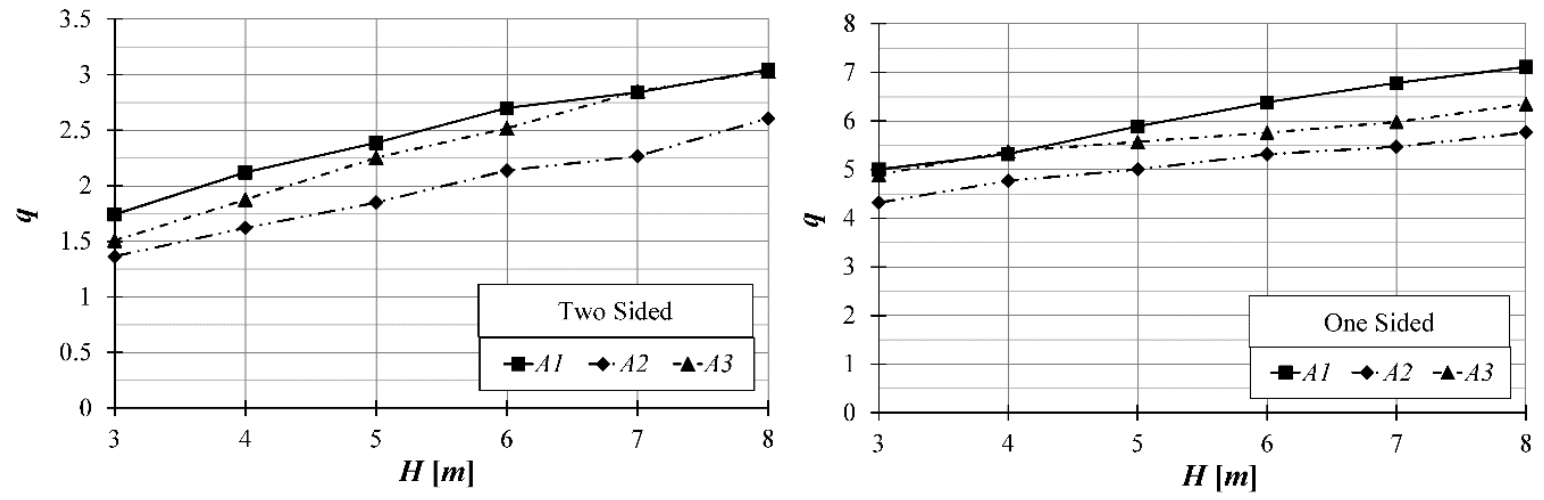

Figure 8. Force reduction factor $q$ versus height $H$-Unreinforced block, $\alpha=7.5^{\circ}$.

Similar results are found for the other considered geometries. For example, considering only seismic inputs compatible with the spectrum $A 2$, Figure 9 shows the results obtained for the three values of slenderness for both mechanisms. For all cases, the $q$ factor increases with increasing angle of slenderness $\alpha$. 

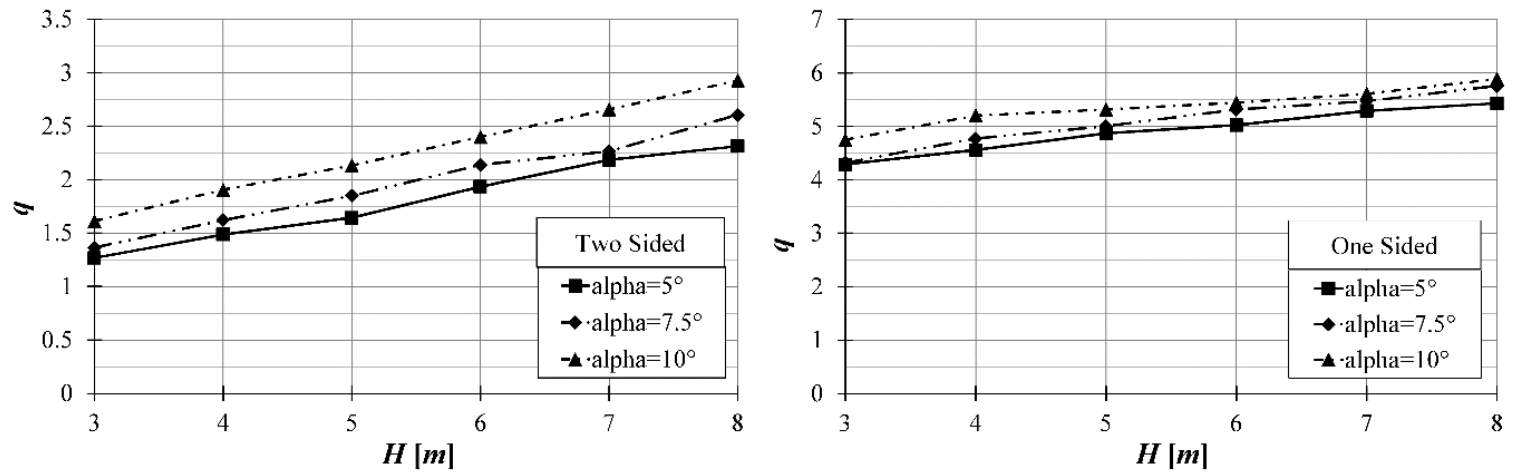

Figure 9. Force reduction factor $q$ versus height $H$-Unreinforced block, Spectrum $A 2$.

\subsection{Force Reduction Factor of the Restrained Rocking Block}

Once the seismic overstrength of the unreinforced rocking masonry wall has been briefly identified, in the following the effects of the retrofitting technique object of the present paper is described. Assuming an angle of slenderness equal to $7.5^{\circ}$, Figure 10 shows, for centred and external GFRP retrofitting system, the trend of the $q$ factor varying the height of the masonry block, for both cases of bilateral and unilateral mechanism. The spectrum $A 2$ and the three values of the cross section of the composite rebars have been set. A slight increase and decrease of the force reduction factor with the height of the block are found for two and one-sided mechanism, respectively. As expected, an increase with the amount of reinforcement is obtained for all cases. Same results are obtained for other slenderness angles and seismic inputs.
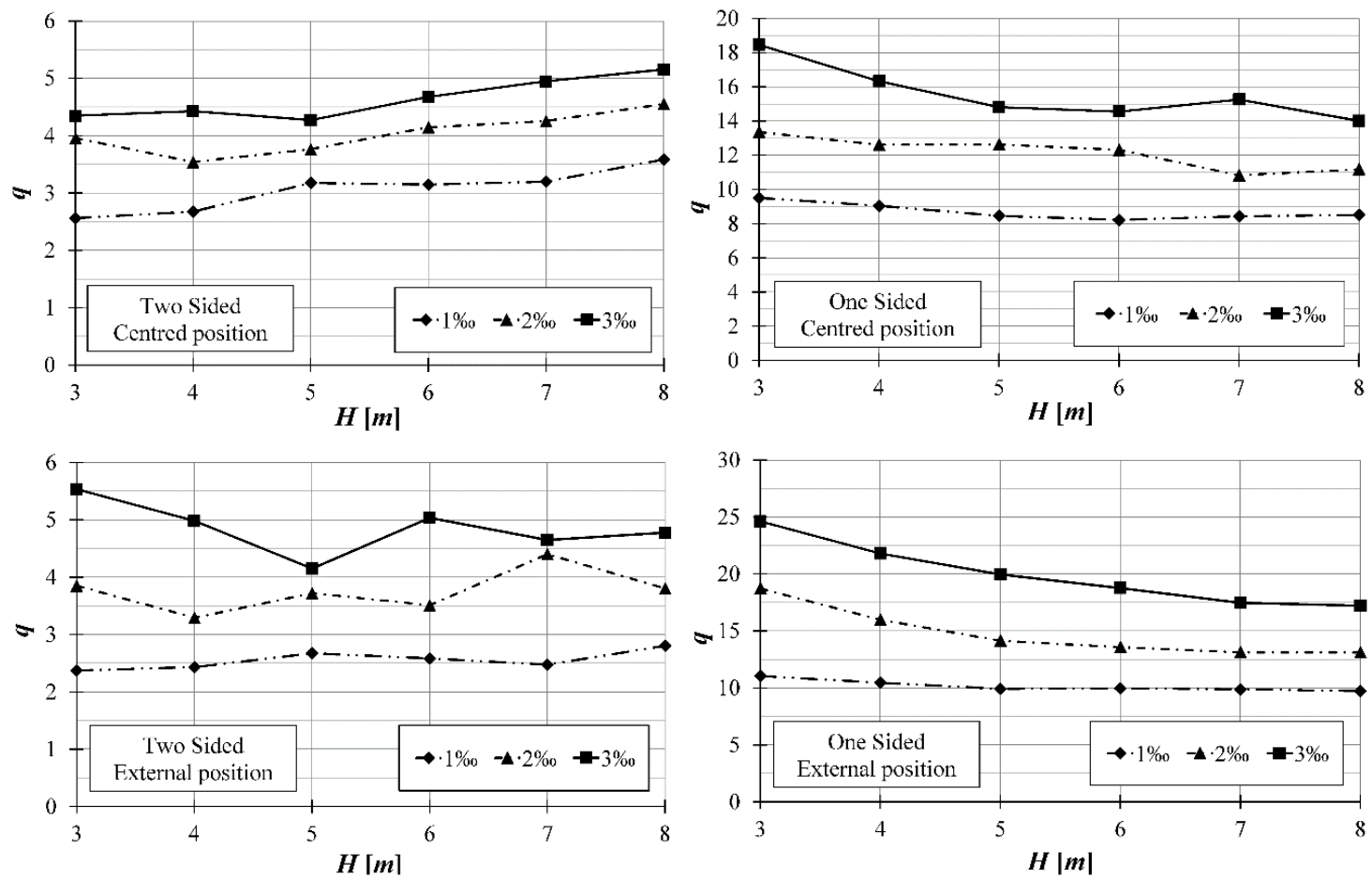

Figure 10. $q$ factor versus height $H-\alpha=7.5^{\circ}$, Spectrum $A 2$, GFRP material.

In Figure 11 the $q$ factors versus the height of the block are plotted for both mechanisms and positions of the vertical rebars characterized by a cross section equal to $1 \%$. The artificial ground motions used are spectrum-compatible with the elastic acceleration response spectrum $A 2$. Each graph refers to the three angles of slenderness $\alpha$ previously defined, equal to $5^{\circ}, 7.5^{\circ}$ and $10^{\circ}$ respectively. The outcomes of the numerical analyses confirm the previously described trends. Furthermore, the $q$ 
factor increases with increasing slenderness of the element. This outcome is more evident in case of two-sided mechanism, for the lowest value of the considered angles of slenderness.
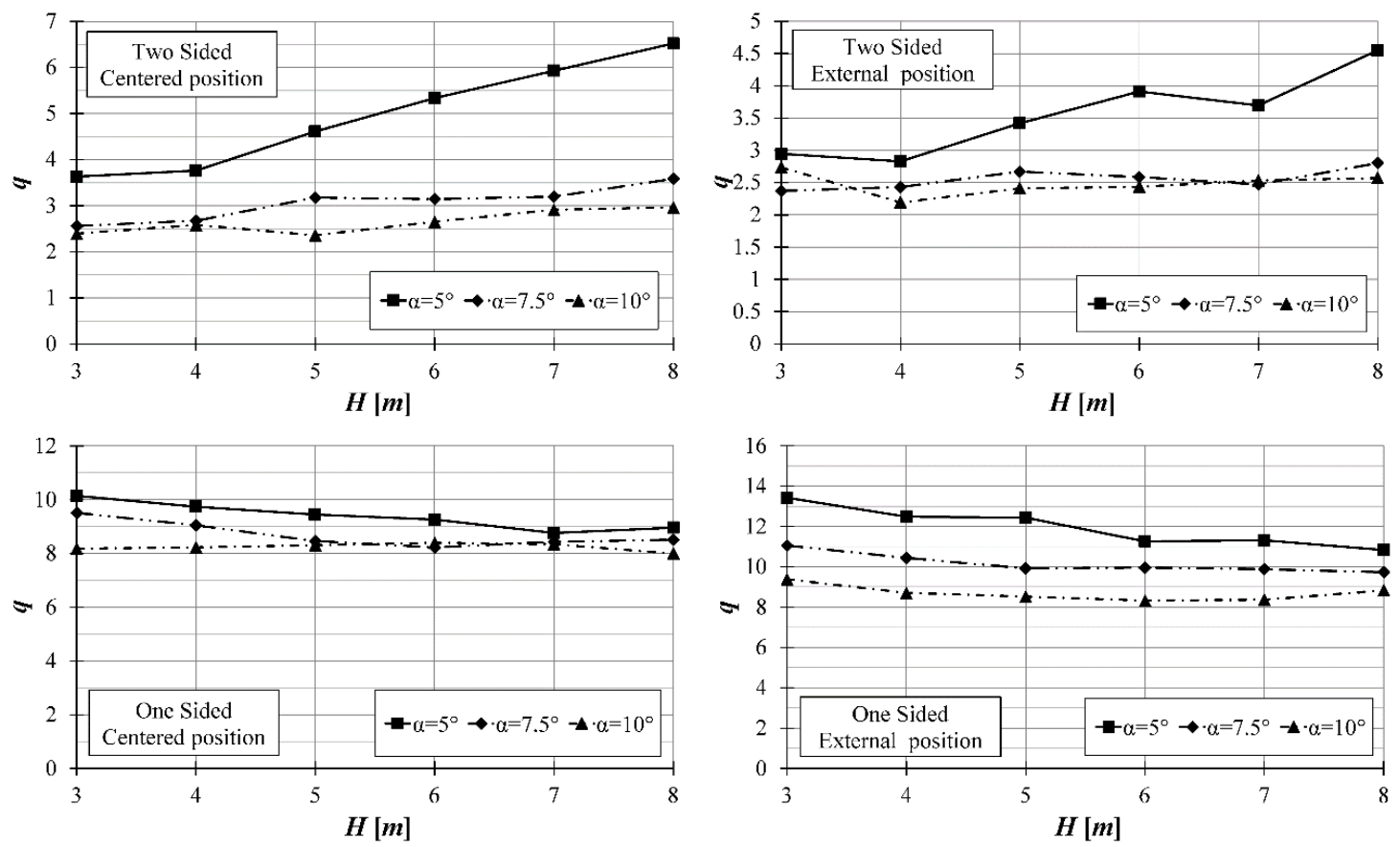

Figure 11. Force reduction factor versus height $H-\rho=1 \%$, Spectrum $A 2$, GFRP material.

Figure 12 shows the $q$ factors versus the height of the block varying the elastic acceleration response spectrum (A1, A2 or A3, respectively), with reference to masonry elements characterized by an angle of slenderness equal to $7.5^{\circ}$ and a cross section of the vertical rebars equal to $1 \%$ o. Both mechanisms (bilateral and unilateral) and both positions of the GFRP retrofitting system (centred and external) are here considered. A lower variability of the results in case of unilateral mechanism is found.
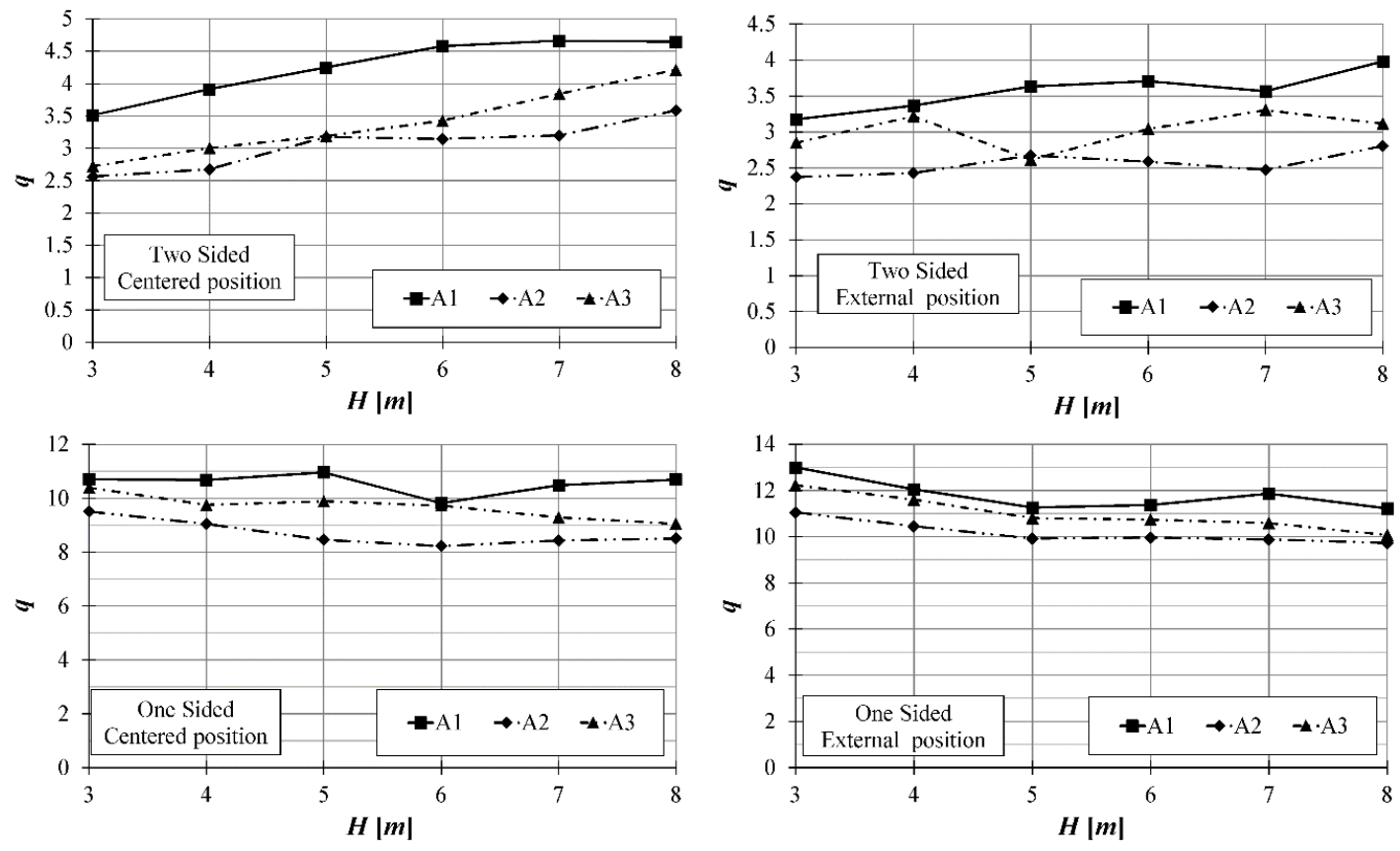

Figure 12. Force reduction factor versus height $H-\alpha=7.5^{\circ}, \rho=1 \%$, GFRP material. 


\subsection{Level of Seismic Improvement of the Restrained Rocking Block}

With the aim to investigate the effectiveness of the retrofitting technique, the results previously plotted are shown in Figure 13 in terms of level of seismic improvement, defined as the ratio between the dynamic collapse accelerations of the reinforced and unreinforced elements ( $a_{R}$ and $a_{U R}$, respectively). As it can be noted, for all considered values of the cross section of the GFRP retrofitting system, the level of seismic improvement decreases with increasing values of the height $H$ of the masonry block. In fact, from the analysis of Equation (12), having fixed the angle of slenderness and the geometrical and mechanical properties of the vertical restraints (i.e., elastic modulus and area of the cross-section), the term related to the presence of the restraints decreases with increasing height $H$, i.e., with the element mass $m$.
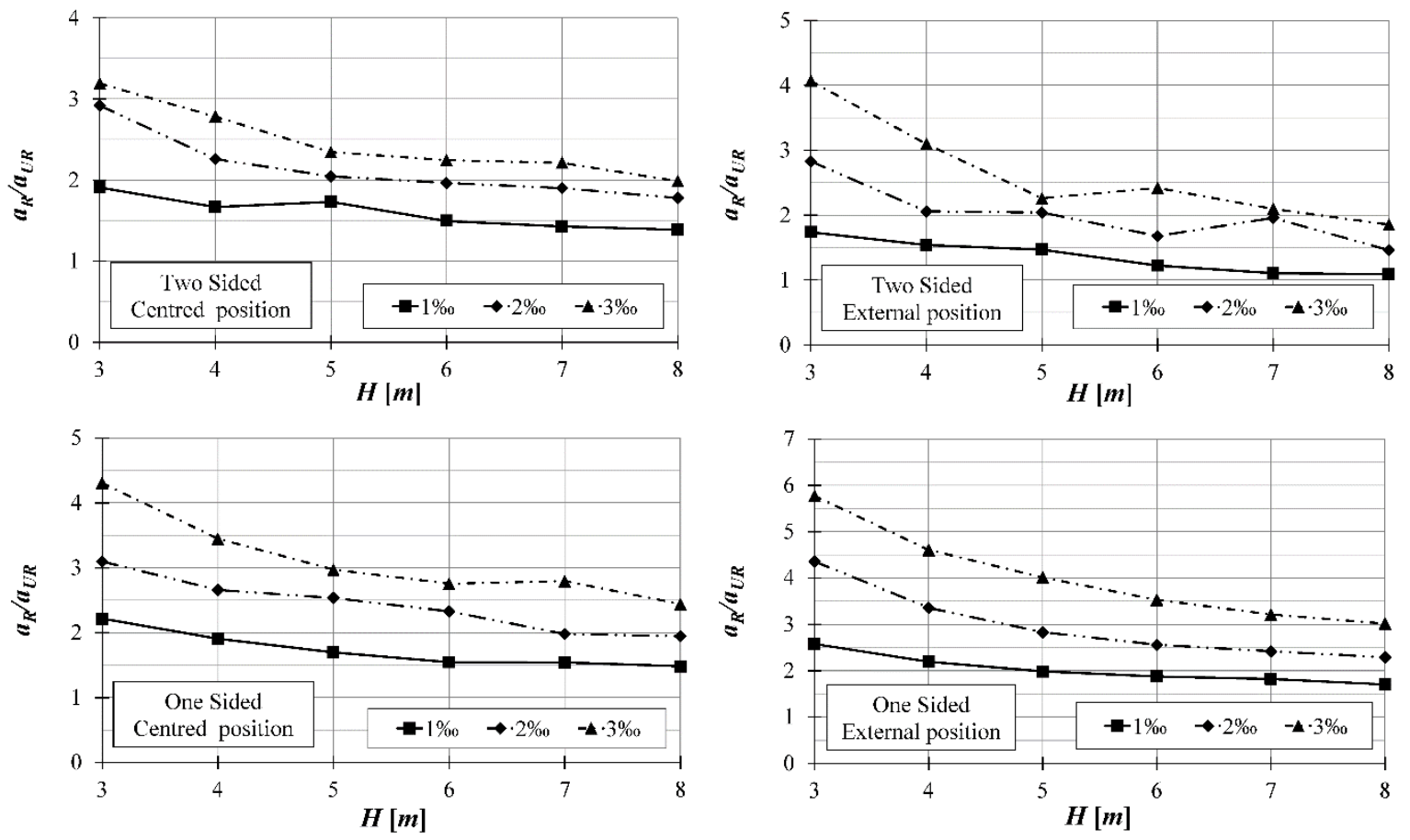

Figure 13. Level of seismic improvement versus height $H-\alpha=7.5^{\circ}$, Spectrum $A 2$, GFRP material.

Similarly, Figure 14 shows the level of seismic improvement versus the height of the block varying the angle of slenderness. In particular, the graphs refer to a GFRP retrofitting system with a percentage $\rho$ equal to $2 \%$ and to artificial ground motions spectrum-compatible with the elastic acceleration response spectrum $A 2$.

Furthermore, with reference to masonry elements characterized by $\alpha$ equal to $7.5^{\circ}$ and $\rho$ equal to $2 \%$, Figure 15 shows the level of seismic improvement versus the height varying the elastic acceleration response spectrum (A1, A2 or A3, respectively). As it can be noted, for the analysed cases, this parameter is slightly affected by the seismic input. 

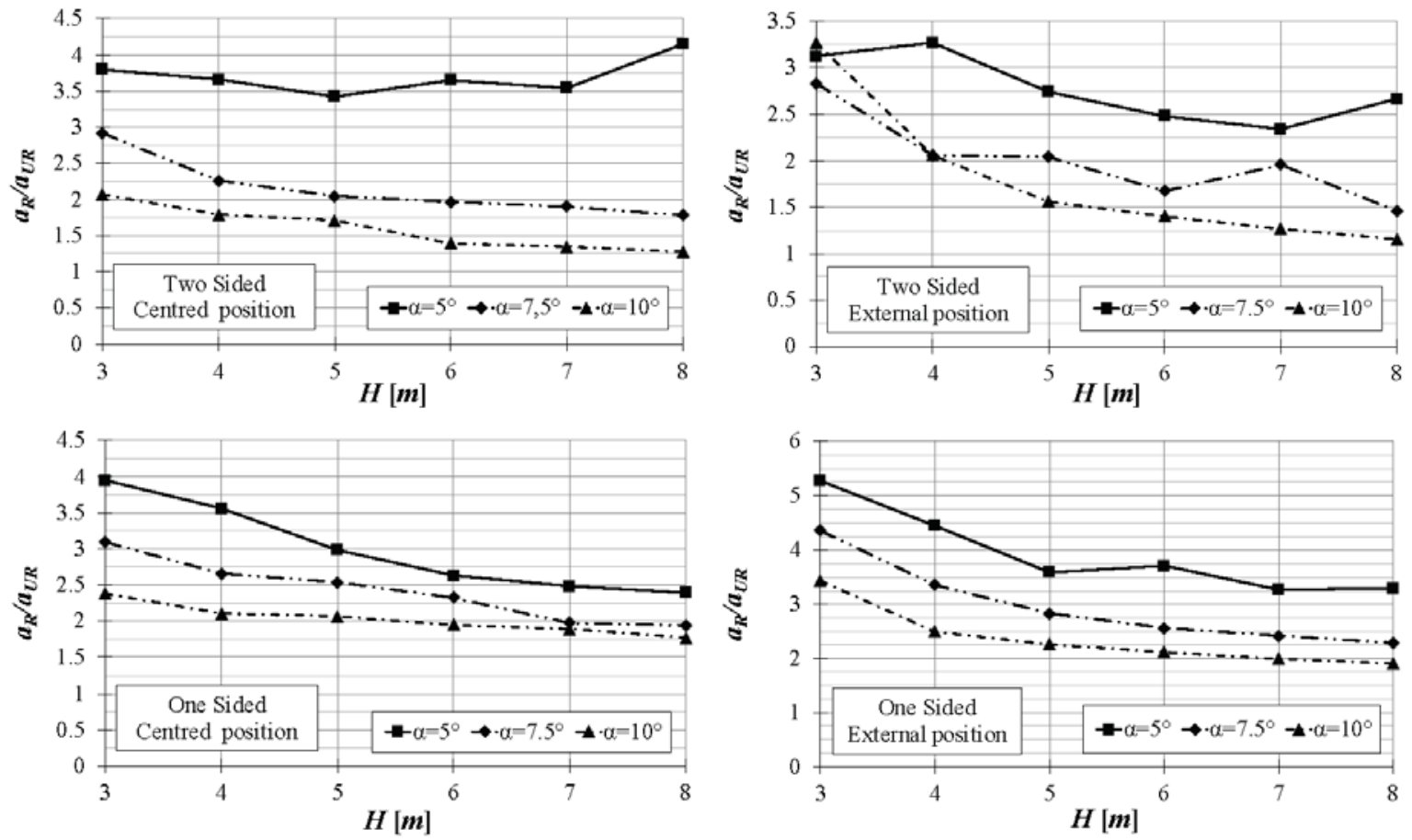

Figure 14. Level of seismic improvement versus height $H-\rho=2 \%$, Spectrum $A 2$, GFRP material.
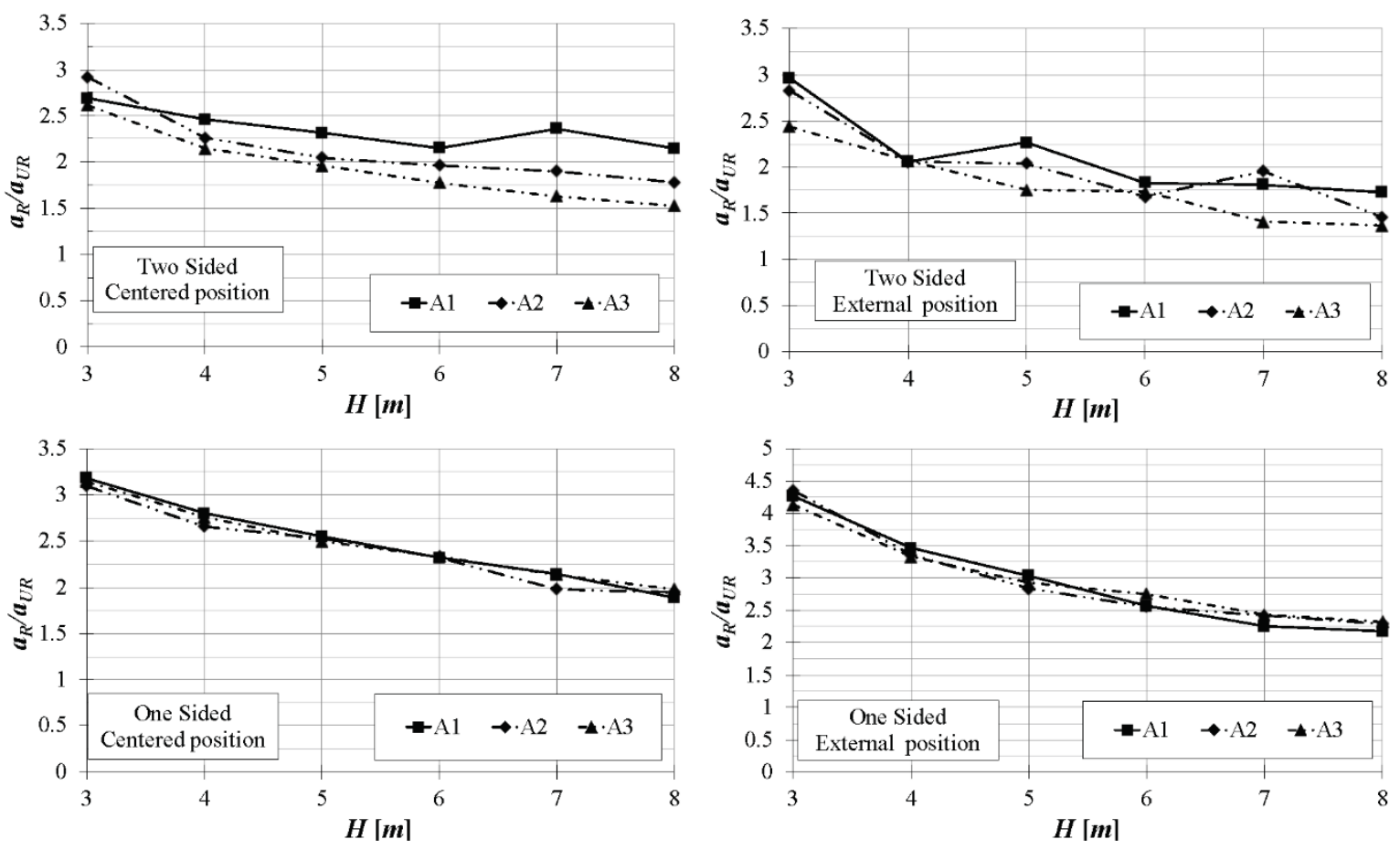

Figure 15. Level of seismic improvement versus height $H-\alpha=7.5, \rho=2 \%$, GFRP material.

Figure 16 shows the trend of the level of seismic improvement for a masonry block with an angle of slenderness equal to $7.5^{\circ}$ and an area of the vertical rebars equal to $1 \%$, undergoing to both two-sided and one-sided mechanisms, varying the height $H$ and the typology of composite material. The artificial ground motions used are spectrum-compatible with the elastic acceleration response spectrum $A 2$. It is worth to note that the level of seismic improvement decreases with increasing values of the height $H$ for all considered materials of vertical restraints. The most effective retrofitting technique is the one realized with external CFRP rebars. Vice versa, lower values of the level of seismic improvement are 
found with centred GFRP anchors. The effectiveness of the retrofitting system is clearly related to the strength or stiffness of the vertical restraints. From Equation (12), the term related to the presence of the restraints increases with increasing values of the elastic modulus $E$.
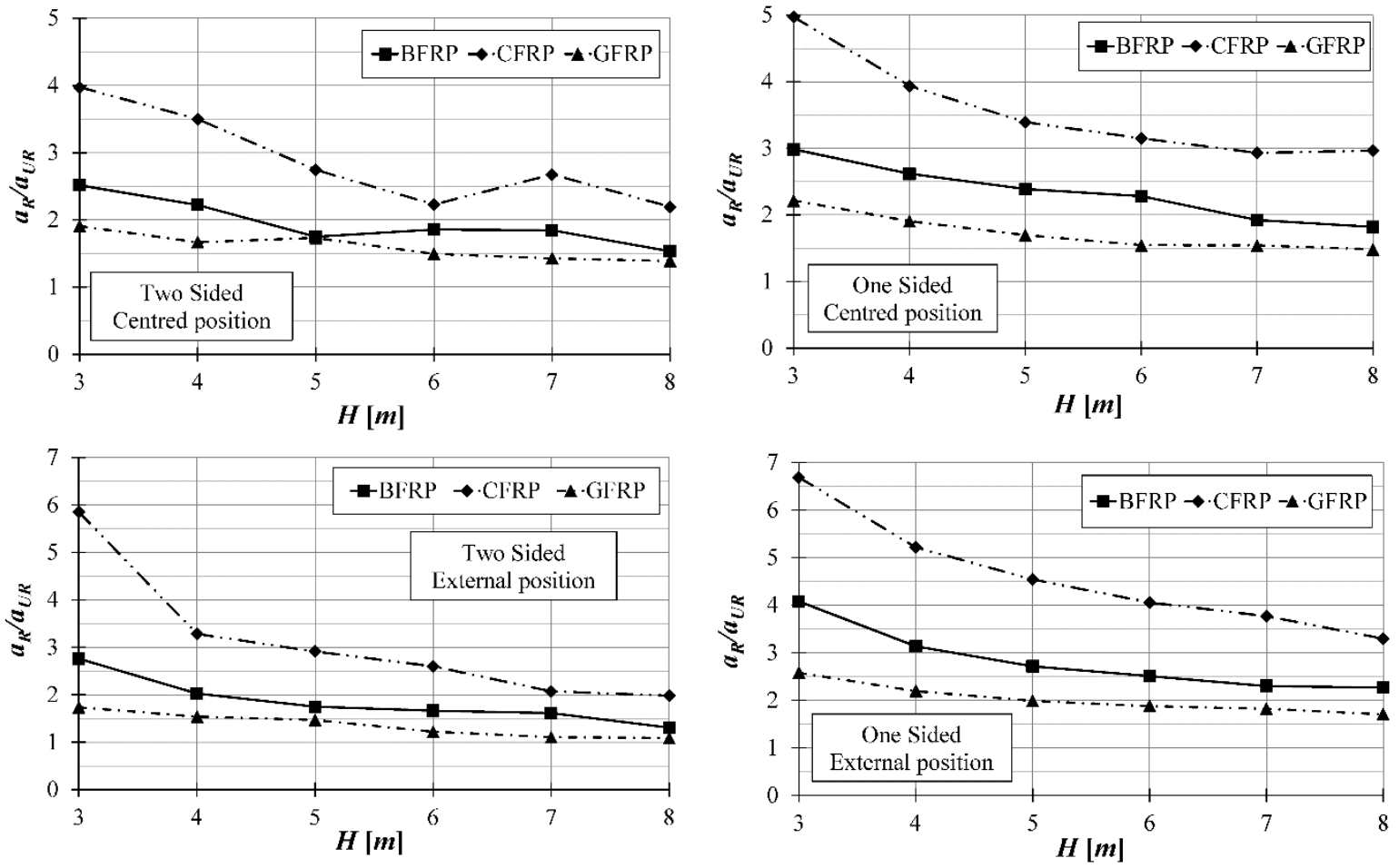

Figure 16. Level of seismic improvement varying composite material $-\alpha=7.5^{\circ}, \rho=1 \%$, Spectrum $A 2$.

The obtained results allow highlighting the effectiveness of the analysed retrofitting technique. It is in fact shown that adequate strength increments are already found with low percentages of reinforcement of around $1 \%$.

\section{Conclusions}

In this paper, the out-of-plane response of masonry elements retrofitted with vertical composite rebars is analytically investigated in the framework of the dynamic equation of motion of the rigid body. Different types of composite material are investigated, glass-fibres or GFRP, basalt-fibres or $B F R P$ and carbon-fibres or CFRP. Furthermore, two different layouts are analysed, consisting in centred or external vertical rebars. The possibility of activation of two local collapse mechanisms is considered: the two-sided rocking, which occurs when the boundary conditions of the masonry wall allow a bilateral motion, or the most common one sided rocking, where only unilateral rotation can occur.

The behaviour of the retrofitted masonry wall is investigated by means of numerical analyses, carried out by solving the dynamic equation of a restrained rocking block excited by a seismic time history. In order to provide useful design indicators, the dynamic analyses are carried out considering sets of spectrum compatible accelerograms, properly defined according the Eurocode 8 provision [54]. Moreover, the obtained results are shown in terms of force reduction factor $q$, defined as the ratio between the seismic acceleration value causing the collapse of the masonry element and the one corresponding to the activation of the rocking motion. The effectiveness of the retrofitting technique is finally expressed in terms of level of seismic improvement, defined as the ratio between the dynamic collapse accelerations of the reinforced $\left(a_{R}\right)$ and unreinforced elements $\left(a_{U R}\right)$.

A parametric analysis is performed, numerically solving the dynamic equation of motion with increasing magnitude of the seismic action in order to find the collapse condition of the block. Aiming to understand the influence of the main parameters of the model on the global response of the system, 
the analyses are carried out by varying the geometrical characteristics of the block, the features of the seismic input, the material and the position of the vertical anchors and the type of local mechanism.

Both responses of unreinforced and reinforced elements are influenced by the characteristics of the seismic input, vice versa, the level of seismic improvement seems to be independent from them.

It is worth to note that the level of seismic improvement decreases with increasing values of the height $H$ and increases with increasing slenderness of the element, for all considered cases. The most effective retrofitting technique is the one realized with external CFRP rebars. Vice versa, the lower values of the level of seismic improvement are found with centred GFRP anchors.

In the case of GFRP reinforcement, a six-fold increase in the level of seismic performance with increasing the amount of vertical reinforcement is found in the one sided mechanism for elements characterized by a height $H$ equal to $3 \mathrm{~m}$, a slenderness $\alpha=7.5^{\circ}$ and $\rho=3 \%$ in the external position. For the same elements (one sided mechanism, external reinforcement, $H=3 \mathrm{~m}, \alpha=7.5^{\circ}$ ), in case of lower value of reinforcement amount $(\rho=1 \%$ o), the seismic improvement can reach values of about $6.5,4.0$ and 2.5 by applying carbon-based, basalt-based or glass-based FRP, respectively.

Finally, the outcomes of the parametric analysis highlights the effectiveness of the analysed retrofitting technique, even if further insights are required on both the numerical and experimental field.

Author Contributions: Investigation, S.C. and F.D.C.; Methodology, S.C. and F.D.C.; Supervision, F.D.C. and S.I.; Validation, S.C.; Writing-original draft, S.C., F.D.C. and S.I.; Writing-review \& editing, S.C., F.D.C. and S.I. All authors have read and agreed to the published version of the manuscript.

Funding: This research received no external funding.

Conflicts of Interest: The authors declare no conflict of interest.

\section{References}

1. Spence, R.; D’Ayala, D. Damage assessment and analysis of the 1997 Umbria-Marche earthquakes. Struct. Eng. Int. 1999, 9, 229-233. [CrossRef]

2. Goretti, A.; Di Pasquale, G. Building inspection and damage data for the 2002 Molise, Italy, earthquake. Earthq. Spectra 2004, 20, S167-S190. [CrossRef]

3. Ferlito, R.; Guarascio, M.; Zucconi, M. Assessment of a vulnerability model against post-earthquake damage data: The case study of the historic city centre of L'Aquila in Italy. In Proceedings of the 9th International Conference on Earthquake Resistant Engineering Structures, A Coruña, Spain, 8-10 July 2013; pp. $393-404$.

4. Colonna, S.; Imperatore, S.; Zucconi, M.; Ferracuti, B. Post-Seismic Damage assessment of a historical masonry building: The case study of a school in Teramo. In Key Engineering Materials; Trans Tech Publications Ltd.: Zurich, Switzerland, 2017; Volume 747, pp. 620-627.

5. Zucconi, M.; Ferlito, R.; Sorrentino, L. Simplified survey form of unreinforced masonry buildings calibrated on data from the 2009 L'Aquila earthquake. Bull. Earthq. Eng. 2018, 16, 2877-2911. [CrossRef]

6. Zucconi, M.; Ferlito, R.; Sorrentino, L. Validation and extension of a statistical usability model for unreinforced masonry buildings with different ground motion intensity measures. Bull. Earthq. Eng. 2020, 18, 767-795. [CrossRef]

7. Borri, A.; Corradi, M.; Castori, G.; De Maria, A. A method for the analysis and classification of historic masonry. Bull. Earthq. Eng. 2015, 13, 2647-2665. [CrossRef]

8. Borri, A.; Corradi, M.; De Maria, A.; Sisti, R. Calibration of a visual method for the analysis of the mechanical properties of historic masonry. Procedia Struct. Integr. 2018, 11, 418-427. [CrossRef]

9. Lourenço, P.B.; Mendes, N.; Ramos, L.F.; Oliveira, D.V. Analysis of masonry structures without box behavior. Int. J. Archit. Herit. 2011, 5, 369-382. [CrossRef]

10. Sorrentino, L.; Cattari, S.; Da Porto, F.; Magenes, G.; Penna, A. Seismic behaviour of ordinary masonry buildings during the 2016 central Italy earthquakes. Bull. Earthq. Eng. 2018, 17, 1-25. [CrossRef]

11. De Felice, G. Out-of-plane seismic capacity of masonry depending on wall section morphology. Int. J. Archit. Herit. 2011, 5, 1-17. [CrossRef]

12. Giuffrè, A. A mechanical model for statics and dynamics of historical masonry buildings. In Protection of the Architectural Heritage Against Earthquakes; Springer: Vienna, Austria, 1996; pp. 71-152. 
13. Lagomarsino, S. On the vulnerability assessment of monumental buildings. Bull. Earthq. Eng. 2006, 4, 445-463. [CrossRef]

14. Lagomarsino, S. Seismic assessment of rocking masonry structures. Bull. Earthq. Eng. 2015, 13, 97-128. [CrossRef]

15. Giresini, L.; Sassu, M.; Sorrentino, L. In situ free-vibration tests on unrestrained and restrained rocking masonry walls. Earthq. Eng. Struct. Dyn. 2018, 47, 3006-3025. [CrossRef]

16. Giresini, L.; Pantò, B.; Caddemi, S.; Caliò, I. Out-of-plane seismic response of masonry façades using discrete macro-element and rigid block models. In Proceedings of the 7th International Conference on Computational Methods in Structural Dynamics and Earthquake Engineering, Crete, Greece, 24-26 June 2019.

17. D'Ayala, D.F.; Speranza, E. Definition of collapse mechanisms and seismic vulnerability of historic masonry buildings. Earthq. Spectra 2003, 19, 479-509. [CrossRef]

18. Decanini, L.; De Sortis, A.; Goretti, A.; Langenbach, R.; Mollaioli, F.; Rasulo, A. Performance of masonry buildings during the 2002 Molise, Italy, earthquake. Earthq. Spectra 2004, 20, S191-S220. [CrossRef]

19. D'Ayala, D.F.; Paganoni, S. Assessment and analysis of damage in L'Aquila historic city centre after 6th April 2009. Bull. Earthq. Eng. 2011, 9, 81-104. [CrossRef]

20. Dizhur, D.; Ingham, J.; Moon, L.; Griffith, M.; Schultz, A.; Senaldi, I.; Ventura, C. Performance of masonry buildings and churches in the 22 February 2011 Christchurch earthquake. Bull. New Zealand Soc. Earthq. Eng. 2011, 44, 279-296. [CrossRef]

21. Colonna, S.; Imperatore, S.; Ferracuti, B. The 2016 central Italy earthquake: Damage and vulnerability assessment of churches. In Proceedings of the International Masonry Society Conferences, Milan, Italy, 9-11 July 2018; pp. 2425-2440.

22. Zucconi, M.; Ferlito, R.; Sorrentino, L. Verification of a usability model for unreinforced masonry buildings with data from the 2002 Molise, southern Italy, eartqhuake. In Proceedings of the International Masonry Society Conferences, Milan, Italy, 9-11 July 2018; pp. 680-688.

23. Sorrentino, L.; Kunnath, S.; Monti, G.; Scalora, G. Seismically induced one-sided rocking response of unreinforced masonry façades. Eng. Struct. 2008, 30, 2140-2153. [CrossRef]

24. Sorrentino, L.; Al Shawa, O.; Decanini, L.D. The relevance of energy damping in unreinforced masonry rocking mechanisms. Exp. Anal. Investig. Bull. Earthq. Eng. 2011, 9, 1617-1642. [CrossRef]

25. Shawa, O.A.; de Felice, G.; Mauro, A.; Sorrentino, L. Out-of-plane seismic behaviour of rocking masonry walls. Earthq. Eng. Struct. Dyn. 2012, 41, 949-968. [CrossRef]

26. Giresini, L.; Fragiacomo, M.; Lourenço, P.B. Comparison between rocking analysis and kinematic analysis for the dynamic out-of-plane behavior of masonry walls. Earthq. Eng. Struct. Dyn. 2015, 44, 2359-2376. [CrossRef]

27. Coccia, S.; Di Carlo, F.; Forino, G. Strength of cracked masonry buttresses under horizontal loads. In Brick and Block Masonry: Trends, Innovations and Challenges-Proceedings of the 16th International Brick and Block Masonry Conference, IBMAC, Padova, Italy, 26-30 June 2016; CRC Press: Boca Raton, FL, USA, 2016; pp. 155-164.

28. Coccia, S.; Di Carlo, F.; Imperatore, S. Force reduction factor for out-of-plane simple mechanisms of masonry structures. Bull. Earthq. Eng. 2017, 15, 1241-1259. [CrossRef]

29. Como, M.; Di Carlo, F. Rocking of cracked masonry walls under constant impulse acceleration. In Proceedings of the AIMETA 2017 XXIII Conference, Salerno, Italy, 4-7 September 2017; pp. 1379-1401.

30. Di Carlo, F.; Coccia, S.; Como, M. Rocking in presence of cracking of masonry wall piers. Key Eng. Mater. 2017, 747, 686-693. [CrossRef]

31. Como, M.; Di Carlo, F.; Coccia, S. Dynamic response of rocking cracked masonry walls. Meccanica 2019, 54, 381-398. [CrossRef]

32. Casolo, S. Modelling the out-of-plane seismic behaviour of masonry walls by rigid elements. Earthq. Eng. Struct. Dyn. 2000, 29, 1797-1813. [CrossRef]

33. Peña, F.; Prieto, F.; Lourenço, P.B.; Campos Costa, A.; Lemos, J.V. On the dynamics of rocking motion of single rigid-block structures. Earthq. Eng. Struct. Dyn. 2007, 36, 2383-2399. [CrossRef]

34. Caliò, I.; Marletta, M.; Pantò, B. A new discrete element model for the evaluation of the seismic behaviour of unreinforced masonry buildings. Eng. Struct. 2012, 40, 327-338. [CrossRef]

35. Bhattacharya, S.; Nayak, S.; Dutta, S.C. A critical review of retrofitting methods for unreinforced masonry structures. Int. J. Disaster Risk Reduct. 2014, 7, 51-67. [CrossRef] 
36. De Santis, S.; de Felice, G.; Napoli, A.; Realfonzo, R. Strengthening of structures with Steel Reinforced Polymers: A state-of-the-art review. Compos. Part B Eng. 2014, 104, 87-110. [CrossRef]

37. De Santis, S.; de Felice, G. Traditional and innovative techniques for the seismic retrofitting of masonry buildings. In Proceedings of the SECED 2015 Conference: Earthquake Risk and Engineering towards a Resilient World, Cambridge, UK, 9-10 July 2015.

38. Wang, C.; Sarhosis, V.; Nikitas, N. Strengthening/retrofitting techniques on unreinforced masonry structure/element subjected to seismic loads: A literature review. Open Constr. Build. Technol. J. 2018, 14, 12. [CrossRef]

39. Indirli, M.; Castellano, M.G.; Clemente, P.; Martelli, A. Application of shape memory alloy devices: The rehabilitation of the S. Giorgio Church bell tower. In Smart Structures and Materials 2001: Smart Systems for Bridges, Structures, and Highways; International Society for Optics and Photonics: Bellingham, WA, USA, 2001; Volume 4330, pp. 262-272.

40. Diocesi di Reggio Emilia-Guastalla. 2017. Available online: http://www.diocesi.re.it/curia/ufficio-beniculturali-e-nuova-edilizia-di-culto/bandi-e-procedure-negoziate (accessed on 29 July 2019).

41. Formisano, A.; Milani, G. Seismic vulnerability analysis and retrofitting of the SS. Rosario church bell tower in Finale Emilia (Modena, Italy). Front. Built Environ. 2019, 5, 1-12. [CrossRef]

42. Ma, R.; Jiang, L.; He, M.; Fang, C.; Liang, F. Experimental investigations on masonry structures using external prestressing techniques for improving seismic performance. Eng. Struct. 2012, 42, 297-307. [CrossRef]

43. Bailey, S.; Dizhur, D.; Trowsdale, J.; Griffith, M.; Ingham, J.M. Performance of posttensioned seismic retrofit of two stone masonry buildings during the Canterbury earthquakes. J. Perform. Constr. Facil. 2015, 29, 04014111. [CrossRef]

44. Preciado, A.; Sperbeck, S.T.; Ramírez-Gaytán, A. Seismic vulnerability enhancement of medieval and masonry bell towers externally prestressed with unbonded smart tendons. Eng. Struct. 2016, 122, 50-61. [CrossRef]

45. Preciado, A.; Bartoli, G.; Ramírez-Gaytán, A. Earthquake protection of the Torre Grossa medieval tower of San Gimignano, Italy by vertical external prestressing. Eng. Fail. Anal. 2017, 71, 31-42. [CrossRef]

46. Coccia, S.; Di Carlo, F.; Imperatore, S. Seismic behaviour of rocking elements reinforced with composite materials. Key Eng. Mater. 2017, 747, 604-611. [CrossRef]

47. Coccia, S.; Di Carlo, F.; Imperatore, S. Seismic retrofitting of masonry rocking elements with composite rebars. In Proceedings of the 10th International Masonry Conference, Milan, Italy, 9-11 July 2018; pp. 1017-1028.

48. Makris, N.; Zhang, J. Rocking Response and Overturning of Anchored Equipment Under Seismic Excitations; PEER 1999/06; Pacific Earthquake Engineering Research Center, University of California: Berkeley, CA, USA, 1999.

49. Makris, N.; Zhang, J. Rocking response of anchored blocks under pulse-type motions. J. Eng. Mech. 2001, 127, 484-493. [CrossRef]

50. Makris, N.; Black, C.J. Uplifting and overturning of equipment anchored to a base foundation. Earthq. Spectra 2002, 18, 631-661. [CrossRef]

51. Housner, G.W. The behavior of inverted pendulum structures during earthquakes. Bull. Seismol. Soc. Am. 1963, 53, 403-417.

52. Yim, C.S.; Chopra, A.K.; Penzien, J. Rocking response of rigid blocks to earthquakes. Earthq. Eng. Struct. Dyn. 1980, 8, 565-587. [CrossRef]

53. CNR-DT 200 R1/2013. Istruzioni per la Progettazione, l'Esecuzione ed il Controllo di Interventi di Consolidamento Statico mediante l'utilizzo di Compositi Fibrorinforzati. CNR: Rome, Italy, 2013.

54. Ernst \& Sohn. Eurocode 8: “Design of Structures for Earthquake Resistance, Part 1: General Rules, Seismic Action and Rules for Buildings"; CEN-EN 1998-1; BSI British Standards: London, UK, 2005.

55. Chopra, A.K. Dynamics of structures: Theory and applications to earthquake engineering; Prentice Hall: Upper Saddle River, NJ, USA, 1995.

(C) 2020 by the authors. Licensee MDPI, Basel, Switzerland. This article is an open access article distributed under the terms and conditions of the Creative Commons Attribution (CC BY) license (http://creativecommons.org/licenses/by/4.0/). 